\title{
Myosin light chain kinase regulates hearing in mice by influencing the F-actin cytoskeleton of outer hair cells and cochleae
}

\author{
XIA YANG, JUN-GUO WANG, DENG-BIN MA, XIAO-FENG MA, \\ GUANG-JIE ZHU, HAN ZHOU, CHEN-JIE YU, XIAO-YUN QIAN and XIA GAO \\ Department of Otolaryngology-Head and Neck Surgery, Nanjing Drum Tower Hospital \\ Affiliated to Nanjing University Medical School, Nanjing 210008, P.R. China
}

Received September 21, 2013; Accepted January 17, 2014

DOI: $10.3892 /$ ijmm.2014.1634

\begin{abstract}
Myosin light chain kinase (MLCK) phosphorylates myosin regulatory light chains to facilitate its interaction with actin filaments and produce contractile activity. The outer hair cells (OHCs) in the ear contain large amounts of actin and a variety myosins. The stereociliary and somatic motility of $\mathrm{OHCs}$ are closely related to hearing. It appears likely that MLCK may play an important role in acoustic transduction. In this study, we analyzed, both in vivo and in vitro, the OHCs of mice bearing a specific deletion of the MLCK gene and the OHCs of control mice. The phenotype was assessed by auditory function [acoustic brainstem responses (ABRs) and distortion product otoacoustic emissions (DPOAEs)], inner ear morphology and histology. MLCK-deficient mice aged 6-7 months showed impaired hearing, a 5- to $10-\mathrm{dB}$ sound pressure level (SPL) increase in the ABR thresholds, when responding to clicks and tones of different frequencies $(8$ and $16 \mathrm{kHz})(\mathrm{P}<0.05)$. The DPOAE amplitudes of 3-month-old MLCK-deficient mice decreased significantly ( $>10 \mathrm{~dB}$ SPL) at low frequencies $(4,5$ and $6 \mathrm{kHz}$ ). The OHCs in the MLCK-deficient mice increased with abnormal stereocilia. The staining of F-actin and the phosphorylation of the regulatory light chain in MLCK-deficient OHCs was weak. Our results indicate that MLCK may regulate the structure and the motility of stereocilia through F-actin polymerization.
\end{abstract}

\section{Introduction}

Hearing impairment is one of the most common disabling sensory defects in humans and varies according to age of onset

Correspondence to: Dr Xiao-Yun Qian or Xia Gao, Department of Otorhinolaryngology-Head and Neck Surgery, Nanjing Drum Tower Hospital Affiliated to Nanjing University Medical School, No. 321 Zhongshan Road, Nanjing 210008, P.R. China

E-mail: qxy522@163.com

E-mail:xiagao@aliyun.com; xiagaogao@hotmail.com

Key words: myosin light chain kinase, hearing, outer hair cell, stereocilia and severity. Approximately 1 in 500 newborns has congenital hearing loss $(1,2)$. Hearing impairment is a genetically heterogeneous disease; over 300 genes are thought to be necessary for hearing and over 50 deafness-causing genes have been identified $(3,4)$. These genes encode a number of important proteins, such as myosin motors, gap junction proteins, ion channels, transcription factors, F-actin bundle proteins, F-actin crosslinking proteins and other gene expression products that have unknown functions (5-10). Studies on the localization and function of these genes have provided a great deal of insight into the mechanisms of hearing.

Hearing in mammals is characterized by high sensitivity, a wide dynamic range and sharp frequency selectivity. In the mammalian auditory pathway, the sensory receptor cells from the organ of Corti have differentiated into 1 row of inner hair cells (IHCs) on the modiolar side of the tunnel and 3 rows of outer hair cells (OHCs) on the lateral side. OHCs play a considerable role in frequency selectivity and in signal amplification through many cytoskeleton proteins, such as myosin, actin and prestin. The slow and fast motility or the electromotility of OHCs is involved in this process (11-14). The slow motile shortening of OHCs is likely performed by the phosphorylation of proteins in the actin-spectrin network of the cortical cytoskeleton in the lateral cell wall. The plasma membrane of the OHC lateral wall and stereocilia contain a number of proteins, such as myosin, actin, prestin, ankyrin, spectrin and calmodulin (15). It has been previously suggested that a number of conventional myosins play an important role in the development of the inner ear (16); however, the underlying mechanisms remain unknown. Myosin may be regulated by myosin light chain kinase (MLCK) through the phosphorylation of the regulatory light chain (RLC) in smooth muscle cells. Therefore, we hypothesized that MLCK may play an important role in hearing.

MLCK is the principal regulator of various forms of eukaryotic motility. MLCK plays an important role in many functions of non-muscle cells, including cell spreading and migration, neurite growth cone advancement, cytokinesis, cytoskeletal clustering, stress fiber formation, platelet shape changes, secretion, transepithelial permeability and cytoskeletal arrangements, which affect ion currents or ion exchange at the plasma membrane (17-20). The smooth muscle gene $M y l k$ expresses 3 transcripts using alternative promoters, 
including short MLCK, long MLCK and telokin. Short MLCK is expressed in hair cells and is necessary for maintaining membrane stability in IHCs (21). Short MLCK has a catalytic core, a regulatory segment, 3 immunoglobulin-like modules, a fibronectin module, a PEVK repeat-rich region and a 3DFRXXL F-actin binding motif in the $\mathrm{N}$ terminus (22-24). MLCK has been shown to be expressed in IHCs (21). In a recent study, mice carrying a specific deletion of MLCK in the IHCs (MLCK ${ }^{\mathrm{IKO}}$ mice) presented with impaired hearing, whose mutant IHCs produced ball-like structures around their hair bundles in vivo, displayed less resistance to hypoosmotic solution, manifested less membrane F-actin and reduced the phosphorylation of myosin light chain in vitro. The authors demonstrated that MLCK is necessary for maintaining the membrane stability of IHCs (21). The exact role of MLCK in OHCs remains unclear. In the present study, using an animal model of mice with a specific deletion of MLCK in OHCs, we investigated the function and regulatory mechanisms of MLCK in OHCs, and found that MLCK has important functions in OHCs.

\section{Materials and methods}

Generation of MLCK OHC-specific knockout mice. The Institutional Animal Care and Use Committee (IACUC) of the Model Animal Research Center of Nanjing University approved all animal procedures. All experiments were conducted in accordance with the IACUC guidelines (Nanjing, China) (permit no. AP\#MZ3).

Floxed Mylk mice $\left(M y k^{\text {flox/flox }}\right)$ with a congenic background (B6:129) which were crossed with OHC-Cre transgenic mice (25), were kindly provided by the Department of Development Neurobiology, St. Jude Children's Research Hospital (Chicago, IL, USA). The OHC-Cre transgenic mice were generated with a BAC containing the prestin gene to specifically enforce Cre expression in OHCs. The resultant mice (Mylk flox/flox: OHC-Cre; designated as $\left.\mathrm{MLCK}^{\mathrm{OKO}}\right)$ were OHC-specific knockout mice for MLCK. The littermates of $\operatorname{MLCK}^{\mathrm{OKO}}\left(\right.$ Mylk $^{\mathrm{flox} /+}$ : OHC-Cre) were used as controls (CTR). These mice were maintained on a 12-h light/dark cycle under specific pathogen-free (SPF) conditions in standard animal rooms of the National Resource Center for Mutant Mice (NRCMM) of China.

Hearing tests. Acoustic brainstem responses (ABRs) reflect the response of the auditory system to acoustic stimuli. Distortion product otoacoustic emissions (DPOAEs) measure acoustic energy, which is generated in the form of otoacoustic emissions (OAEs), that are produced by OHCs in the cochlea. We measured ABRs and DPOAEs to perform a robust assessment of hearing impairment in mice.

$\mathrm{MLCK}^{\mathrm{OKO}}$ and CTR mice, ranging in age from 2 to 9 months, were used in the experiments. All tests were performed in a single-walled, soundproof booth and were repeated 3 times for each mouse. The mice were anesthetized by an intraperitoneal injection of avertin at an initial dose of $500 \mathrm{mg} / \mathrm{kg}$ body weight and maintained with a half-dose every $20 \mathrm{~min}$. After testing was completed, all mice were kept warm on a heating pad, at $37^{\circ} \mathrm{C}$, until they fully recovered from the anesthesia.
$A B R$ recordings. $\mathrm{ABR}$ waveforms were recorded with subcutaneous needle electrodes at the vertex (active), posterior bulla region of the right ear (reference) and tip of the nose (ground). An outlay trumpet was placed $10 \mathrm{~cm}$ in front of the nasal tip. Click and tone pips of 8,16 and $32 \mathrm{kHz}$ were generated using the evoked generation workstation system 3 (Tucker Davis Technologies Inc.; Gainesville, FL, USA) with computerized SigGen32 software. The response was averaged $(n=1,024)$ and displayed from 110 to $0 \mathrm{~dB}$ with decreasing steps of $5 \mathrm{~dB}$. The threshold of hearing was determined by observing the lowest intensity of sound required to elicit a characteristic waveform.

DPOAE recordings. DPOAEs were recorded and analyzed with workstation system 3 (Tucker Davis Technologies Inc.) using computerized SigGen32 software. The acoustic probe was lengthened with a tapered plastic tube to ensure a tight fit in the external ear canal and the formation of a closed acoustic system. The $\mathrm{f} 2 / \mathrm{f} 1$ frequency ratio was maintained at 1.20 , and the value of $\mathrm{f} 2$ varied from 1 to $12 \mathrm{kHz}$ ( 8 points). The sound intensities at each frequency (f1 and f2) were $65 \mathrm{~dB}$. The signal-to-noise ratios (SNRs) of the DPOAE (2f1-f2) data at the various $\mathrm{f} 2$ values were obtained.

Histopathological analysis. Mice were euthanized with an overdose of avertin and were then perfused with phosphatebuffered solution (PBS) followed by $4 \%$ paraformaldehyde (Sigma-Aldrich, St. Louis, MO, USA). The acoustic capsule was removed. The cochleae were removed through an open window over the apical turn of the cochlea and stored overnight in $4 \%$ paraformaldehyde in PBS at $4^{\circ} \mathrm{C}$. For decalcification, the cochleae were incubated in $10 \%$ ethylenediaminetetraacetic acid (EDTA) (pH 7.4) for 5 days at $4^{\circ} \mathrm{C}$ prior to standard histological examination. Briefly, the specimens were dehydrated in a graded series of ethanol solutions before being embedded in paraffin and the serial sections $(7 \mu \mathrm{m})$ of the cochleae were stained with hematoxylin and eosin (H\&E).

Scanning electron microscopy (SEM) assay. Mice were euthanized with an overdose of avertin and perfused with PBS followed by glutaraldehyde fixative (2.5\% glutaraldehyde in PBS). Cochleae were selected and post-fixed again in glutaraldehyde fixative at $4^{\circ} \mathrm{C}$ for $4-6 \mathrm{~h}$ followed by decalcification. For SEM, the bone and stria vascularis surrounding the cochleae were dissected, and the tectorial membrane was removed to expose the organ of Corti. The organ of Corti was fixed in $1 \%$ osmium tetroxide, dehydrated and critical point-dried. The organ of Corti was sputter-coated with gold and the images were collected using an S-3000 N scanning electron microscope (Hitachi, Tokyo, Japan) at $15 \mathrm{kV}$.

Immunofluorescence assay for inner ear sensory epithelia. The cochleae were removed through the round window, infused with 4\% paraformaldehyde in PBS and post-fixed at $4^{\circ} \mathrm{C}$ for $3 \mathrm{~h}$. Following decalcification in 10\% EDTA overnight at room temperature, the Corti sensory epithelium was dissected from the soft cochlea. The sensory epithelia were permeabilized with $0.5 \%$ Triton X-100 in PBS for $20 \mathrm{~min}$ and washed 3 times with PBS. Non-specific binding was blocked in PBS buffer containing 5\% goat serum, $1 \%$ bovine serum albumin (BSA) and $0.1 \%$ Triton X-100 for $1 \mathrm{~h}$ at room 
Table I. The mean acoustic brainstem response (ABR) thresholds and their variance estimates (standard deviations) for each test, age group of mice and auditory stimulus, and the numbers of mice tested in each group.

\begin{tabular}{|c|c|c|c|c|c|c|}
\hline \multirow[b]{2}{*}{ Mice } & \multirow[b]{2}{*}{ Age } & \multirow[b]{2}{*}{ Click } & \multicolumn{3}{|c|}{ Tone frequency $(\mathrm{kHz})$} & \multirow[b]{2}{*}{$\mathrm{N}$} \\
\hline & & & 8 & 16 & 32 & \\
\hline $\mathrm{MLCK}^{\mathrm{OКО}}$ & $2-3 \mathrm{M}$ & $15.29 \pm 4.13$ & $25.29 \pm 5.72$ & $21.17 \pm 4.51$ & $48.23 \pm 7.69$ & 17 \\
\hline CTR & & $15.00 \pm 4.33$ & $26.76 \pm 3.03$ & $22.05 \pm 3.09$ & $45.88 \pm 4.75$ & 17 \\
\hline MLCK & 4-5 M & $15.47 \pm 3.84$ & $26.19 \pm 5.45$ & $23.09 \pm 8.58$ & $55.0 \pm 16.12$ & 21 \\
\hline CTR & & $14.76 \pm 3.34$ & $26.66 \pm 4.28$ & $20.95 \pm 5.38$ & $51.9 \pm 16.46$ & 21 \\
\hline MLCK $^{\text {Око }}$ & $6-7 \mathrm{M}$ & $20.35 \pm 8.49^{a}$ & $33.21 \pm 8.18^{\mathrm{b}}$ & $37.1 \pm 25.14^{\mathrm{a}}$ & $87.3 \pm 29.64$ & 28 \\
\hline CTR & & $15.68 \pm 4.76^{\mathrm{a}}$ & $28.10 \pm 4.89^{\mathrm{b}}$ & $26.5 \pm 13.03^{\mathrm{a}}$ & $76.5 \pm 28.78$ & 29 \\
\hline MLCK $^{\text {Око }}$ & $8-9 \mathrm{M}$ & $24.5 \pm 11.76$ & $38.7 \pm 20.68$ & $42.5 \pm 29.88$ & $85.0 \pm 30.96$ & 12 \\
\hline CTR & & $25.4 \pm 16.19$ & $35.9 \pm 17.00$ & $38.6 \pm 21.10$ & $88.0 \pm 23.85$ & 11 \\
\hline
\end{tabular}

Data are expessed as the means $\pm \mathrm{SD} .{ }^{a} \mathrm{P}<0.05$, significant difference compared with CTR mice. ${ }^{\mathrm{b}} \mathrm{P}<0.01$, significant difference compared with CTR mice. CTR, control; N, number of mice tested.

temperature. The tissues were incubated with primary antibody overnight at $4^{\circ} \mathrm{C}$ and washed 3 times with $0.1 \%$ Tween in PBS followed by incubation with the secondary antibody for $1.5 \mathrm{~h}$ at room temperature. In the experiments, anti-phospho myosin light chain 2 (Ser 19) antibody (1:150 dilution; Cell Signaling; Cell Signaling Technology, BSN, USA) was used as the primary antibody, and Alexa Fluor 488-conjugated goat anti-rabbit $\operatorname{IgG}$ and Alexa Fluor 555-conjugated goat anti-mouse or anti-rabbit IgG were used as the secondary antibodies (Molecular Probes; Carlsbad, CA, USA). F-actin was labeled by Alexa Fluor 488-conjugated Phalloidin (Invitrogen; Carlsbad, CA, USA), while DAPI (Sigma; Carlsbad, CA, USA) was used to stain the nucleus. Immunofluorescent signals were examined under an Olympus confocal microscope (Olympus, Tokyo, Japan).

Isolation of $\mathrm{OHCs}$ and measurement of the $\mathrm{OHC}$ diameter. Three-month-old mice of either gender were anesthetized by an intraperitoneal injection of avertin. The bullae were excised, and the lateral wall of the cochleae and stria vascularis were removed with a fine needle under a dissection microscope. The organ of Corti was dissected, and OHCs were enzymatically isolated at room temperature with collagenase (type IV Sigma-Aldrich, $1 \mathrm{mg} / \mathrm{ml}$ ). The isolated OHCs were transferred with a glass pipette to a chamber filled with D-Hank's solution, and their diameter was measured using an Olympus confocal microscope. The D-Hank's solution contained $136.9 \mathrm{mM} / 1$ $\mathrm{NaCl}, 5.4 \mathrm{mM} / 1 \mathrm{KCl}, 0.3 \mathrm{mM} / 1 \mathrm{Na}_{2} \mathrm{HPO}_{4}, 4.2 \mathrm{mM} / 1 \mathrm{NaHCO}_{3}$ and $0.4 \mathrm{mM} / 1 \mathrm{KH}_{2} \mathrm{PO}_{4}(300 \mathrm{mOsm} / 1, \mathrm{pH} 7.2)$. ImageJ software was used to analyze the diameter of the OHCs.

Statistical analysis. The data are expressed as the means \pm SEM. Differences concerning the hearing and the diameter of the OHCs between the 2 groups were compared with one-way analysis of variance followed by a StudentNewman-Keul's t-test with a value of $\mathrm{P}<0.05$ considered to indicate a statistically significant difference. We used the $\chi^{2}$ test to analyze the data of the missing and disordered $\mathrm{OHC}$ stereocilia in the apex turn with $\mathrm{P}<0.01$ as the level of signifi- cance. SPSS 17.0 (SPSS Inc., Chicago, IL, USA) software was used for statistical analysis.

\section{Results}

MLCK $K^{O K O}$ mice display an increased $A B R$ threshold and decreased DPOAE amplitudes. We recorded and characterized the ABRs of MLCK ${ }^{\mathrm{OKO}}$ mice that were between 2 and 9 months of age and compared them with those of the control mice. An example of ABR waves is presented in Fig. 1A. The recordings were 10 -msec-long and included a 2 -msec pre-stimulus period. There were typically 4-5 waves in each 10-msec trace, as reported previously by Song et al (26). Table I shows the ABR thresholds of the mice of different ages and at different frequencies.

The ABR thresholds did not differ significantly between the MLCK ${ }^{\mathrm{OKO}}$ mice and CTR mice at 2-5 and 8-9 months of age ( $\mathrm{P}>0.05$ for all frequencies). Compared with the CTR mice, the $\mathrm{MLCK}^{\mathrm{OKO}}$ mice (6-7 months old) displayed a significantly higher threshold in response to clicks $(20.35 \pm 8.49 \mathrm{~dB}$ vs. $15.68 \pm 4.76 \mathrm{~dB}$ of $\mathrm{CTR}, \mathrm{P}<0.05)$ and tones $(8 \mathrm{kHz}$ : $33.21 \pm 8.18 \mathrm{~dB}$ vs. $28.10 \pm 4.89 \mathrm{~dB}$ of $\mathrm{CTR}, \mathrm{P}<0.01 ; 16 \mathrm{kHz}$ : $37.14 \pm 25.14 \mathrm{~dB}$ vs. $26.55 \pm 13.03$ of $\mathrm{CTR}, \mathrm{P}<0.05)$. The mean ABR thresholds between the 2 experimental groups (CTR and $\mathrm{MLCK}^{\mathrm{OKO}}$ mice) are graphically illustrated in Fig. $1 \mathrm{~B}$ and $\mathrm{C}$ for the 6- to 7-month-old age groups.

ABR was used to assess the function of the entire auditory pathway objectively, whereas DPOAE evaluated cochlear function. We measured the DPOAE thresholds of the MLCK ${ }^{\text {OKO }}$ mice and CTR mice at the age of 3 months. In DPOAE testing, the distortion product $2 \mathrm{f} 1-\mathrm{f} 2$ was significantly decreased in the $\mathrm{MLCK}^{\mathrm{OKO}}$ mice compared with the control mice. Fig. 2 illustrates the comparison of the mean and standard error of DPOAE thresholds between the CTR and MLCK ${ }^{\mathrm{OKO}}$ mice. Significant differences were observed between the 2 groups of mice (t-test, $\mathrm{P}<0.01$ at 4,5 and $6 \mathrm{kHz}$ frequencies). The threshold shifts occurred at 4,5 and $6 \mathrm{kHz}$ frequencies, and

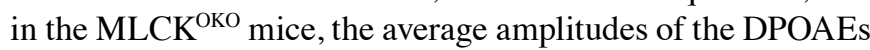
decreased by $>10 \mathrm{~dB}$. 


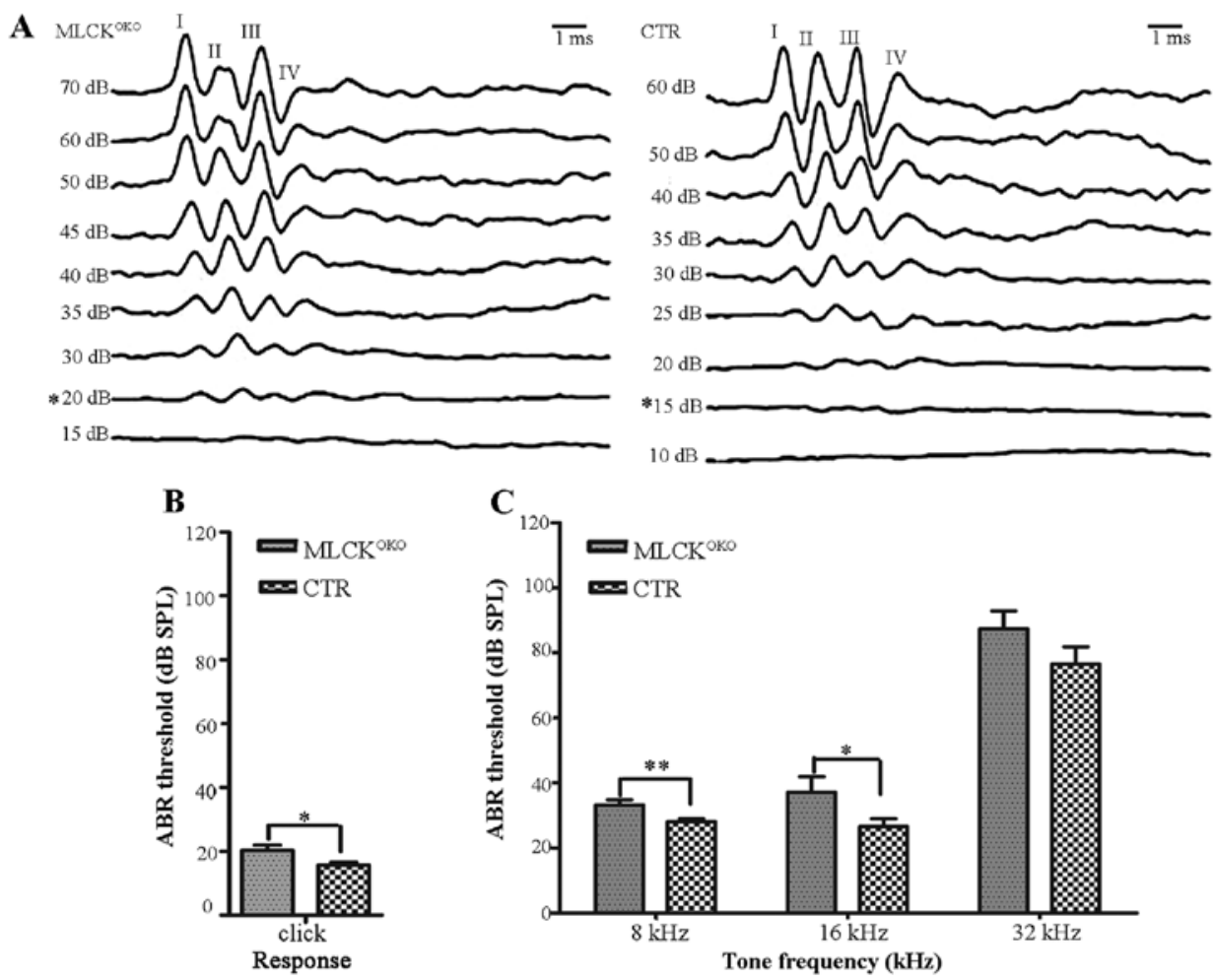

Figure 1. Acoustic brainstem response (ABR) threshold analyses in MLCK OHC-specific knockout (MLCK ${ }^{\text {OKO }}$ ) and control (CTR) mice. (A) Typical example of $\mathrm{ABR}$ measured in MLCK ${ }^{\mathrm{OKO}}$ and CTR mice in response to click stimuli of indicated intensities. *ABR threshold. (B and C) Quantification results of ABR thresholds did not differ significantly between the 6- to 7-month-old CTR $(\mathrm{n}=28)$ and $\mathrm{MLCK}^{\mathrm{OKO}}$ mice $(\mathrm{n}=29)$ for click and tone stimuli. ${ }^{*} \mathrm{P}<0.05$ and ${ }^{* * *} \mathrm{P}<0.01$, significant difference.

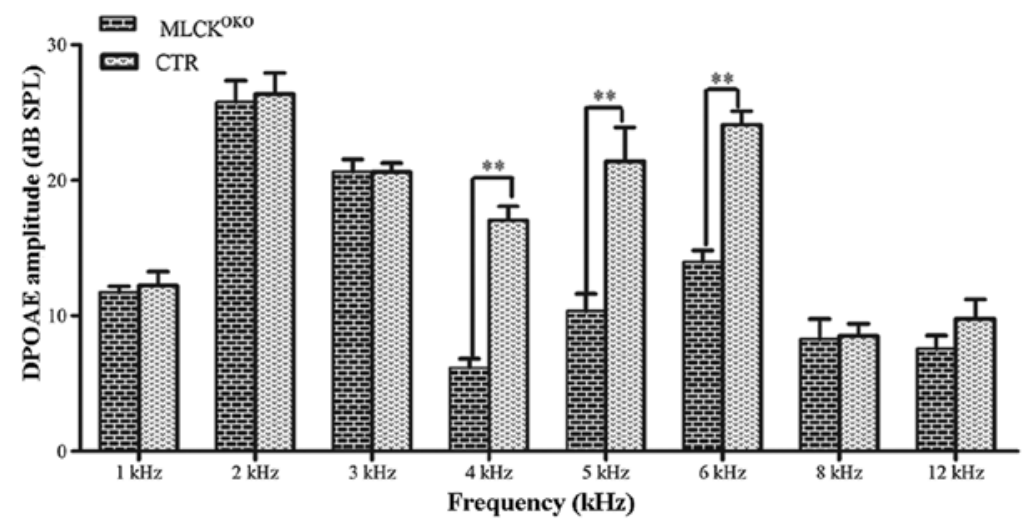

Figure 2. Distortion product otoacoustic emission (DPOAE) analysis at 2f1-f2 in OHC-specific knockout mice for MLCK (MLCK ${ }^{\mathrm{OKO}}$ ) and control (CTR) mice. DPOAE at 2f1-f2 recorded in the ear canal. $\mathrm{MLCK}^{\mathrm{OKO}}$ mice $(\mathrm{n}=11)$ had a significantly smaller distortion product compared with $\mathrm{CTR}$ mice $(\mathrm{n}=14) .{ }^{* *} \mathrm{P}<0.01$, significant difference.

Histological analysis of the cochlea structure. Light microscopy analysis of the cochleae sections displayed the normal architecture of the organ of Corti with IHCs, OHCs, Hensen's cells, stria vascularis and spiral ganglion cells in 3-month-old $\mathrm{MLCK}^{\mathrm{OKO}}$ mice, although these mice displayed impaired hearing function (data not shown).

By contrast, SEM assays of the MLCK ${ }^{\text {ОKО }}$ mice at 3, 5, 6, 7 and 9 months of age revealed the degeneration of the $\mathrm{OHC}$ stereocilia. On the surface preparation of each cochlea, the missing hair cell stereocilia were observed primarily in the
OHCs towards the apex turn of the cochlea, which indicated that MLCK may have some influence on the aggregation of the stereocilia. However, we found fewer OHCs missing stereocilia in the cochlear basilar membrane of the CTR mice. The disarrangement of the $\mathrm{OHC}$ stereociliary bundles was another morphological finding. There was no observable loss of IHC stereocilia through the entire basilar membrane of the cochlea (Fig. 3).

We separately counted the number of missing and disordered OHC stereocilia in the apex turn, and we conducted a 
Table II. Comparative analysis of the missing and disordered outer hair cell (OHC) stereocilia in the apex turn between the CTR and MLCK OHC-specific knockout (MLCK ${ }^{\mathrm{OKO}}$ ) mice.

\begin{tabular}{|c|c|c|c|c|c|c|c|}
\hline $\begin{array}{l}\text { Age } \\
\text { (months) }\end{array}$ & Mice & Missing & Remaining & P-value & Abnormal & Normal & P-value \\
\hline 3 & $\begin{array}{c}\text { MLCK }^{\mathrm{OKO}} \\
\text { CTR }\end{array}$ & $\begin{array}{r}59 \\
2\end{array}$ & $\begin{array}{l}498 \\
402\end{array}$ & $<0.001$ & $\begin{array}{r}395 \\
48\end{array}$ & $\begin{array}{l}164 \\
228\end{array}$ & $<0.001$ \\
\hline 5 & $\begin{array}{c}\text { MLCK }^{\text {OКО }} \\
\text { CTR }\end{array}$ & $\begin{array}{r}30 \\
6\end{array}$ & $\begin{array}{l}308 \\
301\end{array}$ & $<0.001$ & $\begin{array}{r}269 \\
19\end{array}$ & $\begin{array}{r}68 \\
213\end{array}$ & $<0.001$ \\
\hline 6 & $\begin{array}{c}\text { MLCK }^{\text {ОКО }} \\
\text { CTR }\end{array}$ & $\begin{array}{r}30 \\
6\end{array}$ & $\begin{array}{l}310 \\
297\end{array}$ & $<0.001$ & $\begin{array}{l}302 \\
147\end{array}$ & $\begin{array}{r}38 \\
113\end{array}$ & $<0.001$ \\
\hline 7 & $\begin{array}{c}\text { MLCK }^{\text {ОКО }} \\
\text { CTR }\end{array}$ & $\begin{array}{r}103 \\
18\end{array}$ & $\begin{array}{l}456 \\
751\end{array}$ & $<0.001$ & $\begin{array}{l}421 \\
263\end{array}$ & $\begin{array}{l}139 \\
509\end{array}$ & $<0.001$ \\
\hline 9 & $\begin{array}{c}\text { MLCK }^{\text {ОКО }} \\
\text { CTR }\end{array}$ & $\begin{array}{r}136 \\
19\end{array}$ & $\begin{array}{l}633 \\
402\end{array}$ & $<0.001$ & $\begin{array}{l}611 \\
307\end{array}$ & $\begin{array}{l}158 \\
321\end{array}$ & $<0.001$ \\
\hline
\end{tabular}

Data were analyzed by the $\chi^{2}$ test.

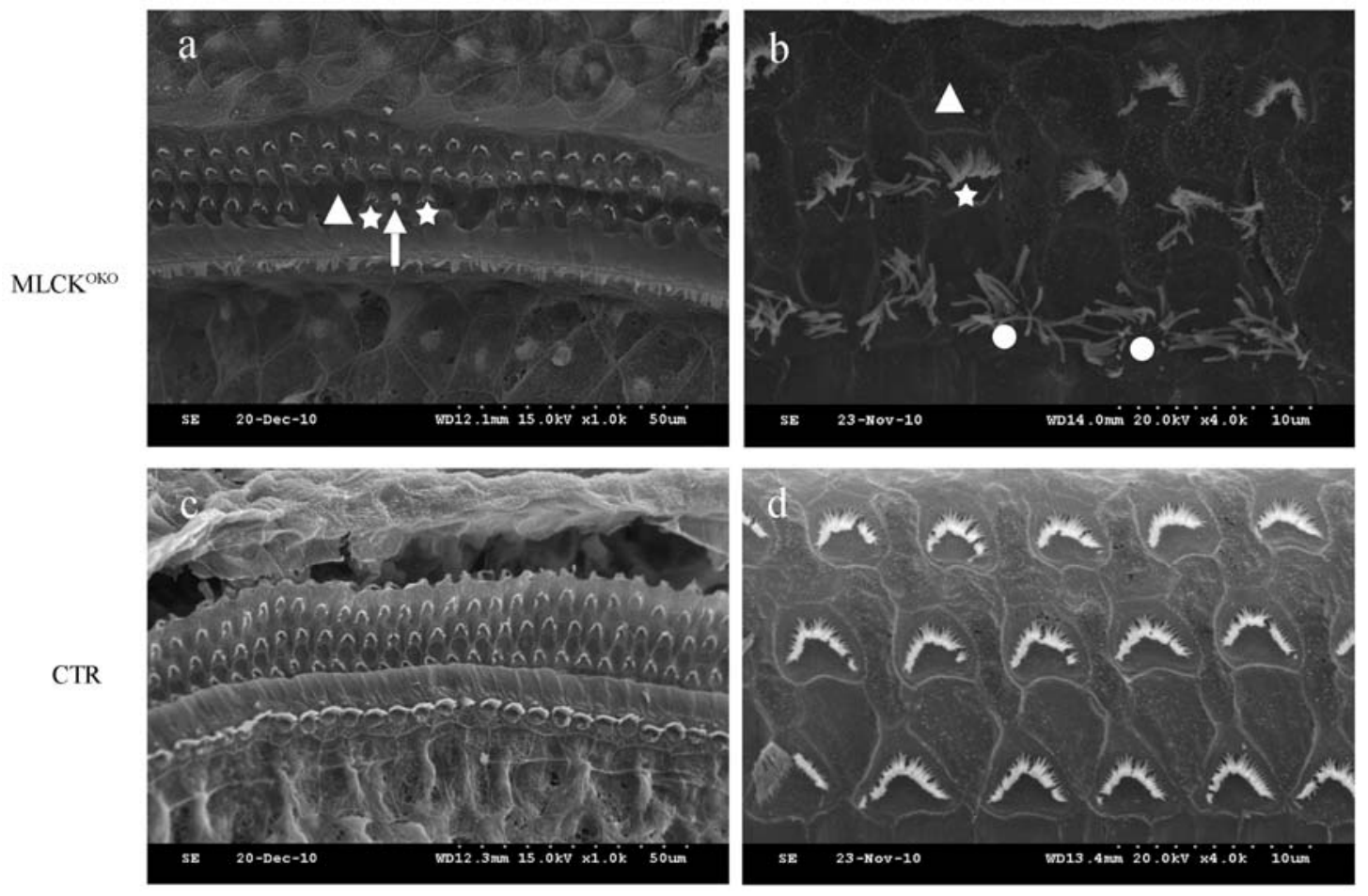

Figure 3. Histology of the cochlea structure. Scanning electron microscopy analyses of MLCK OHC-specific knockout (MLCK $\left.{ }^{\text {OKO }}\right)$ and control (CTR) mice.

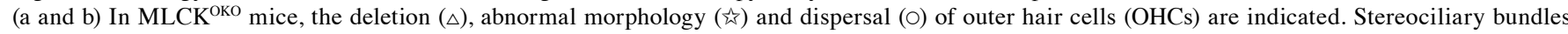
observed mostly in OHCs towards the apex turn of the cochlea, and some ball-like structures around the hair bundles of OHCs were observed occasionally ( $)$ ). (c and d) CTR mice show normal hair bundles on 1 row of IHCs and 3 rows of OHCs on the basal membrane. Scale bars, (a and c) $50 \mu \mathrm{m}$, (b and d) $10 \mu \mathrm{m}$.

$\chi^{2}$ test to analyze these data using SPSS 17.0 software with $\mathrm{P}<0.05$ considered to indicate a statistically significant difference. The results are presented in Table II.

MLCK-deficient OHCs present reduced F-actin and RLC phosphorylation. In order to determine whether the density of F-actin was altered, we stained the inner ear cells with phalloidin. Most of the phalloidin signal was distributed around the
OHC cell membrane and the button area. The CTR IHCs had strong and continuous F-actin staining in addition to membrane structure. However, F-actin staining in the MLCK-deficient OHCs was weak and discontinuous (Fig. 4A).

MLCK is a dedicated kinase for myosin light chain phosphorylation. RLC phosphorylation is also involved in various cellular processes, in addition to its important role in smooth muscle contraction. It has been demonstrated that 

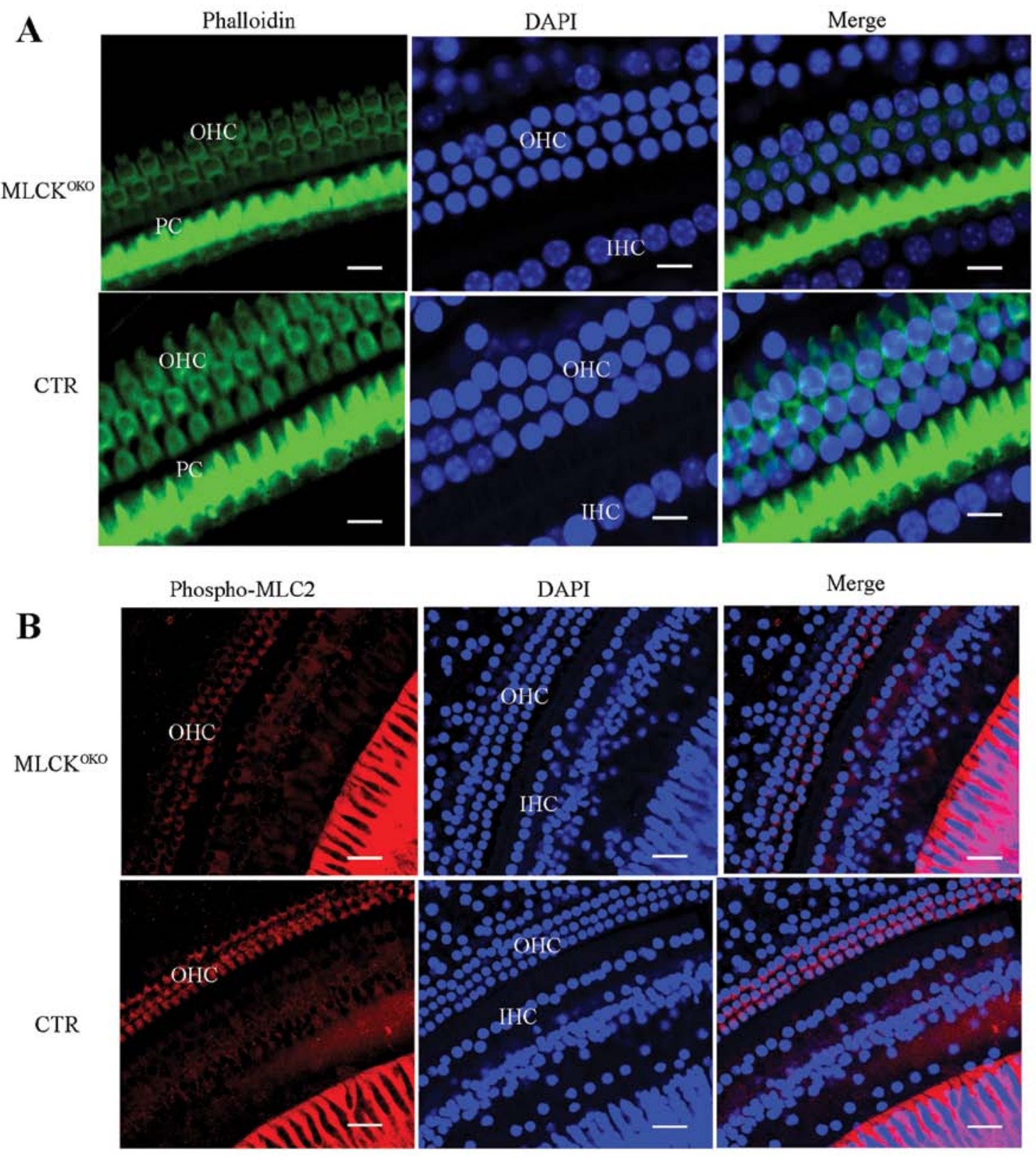

Figure 4. Immunofluorescence of the MLCK-deficient outer hair cells (OHCs). (A) Actin cytoskeleton in the basal membrane (BM) of Corti. In the BM of MLCK OHC-specific knockout ( $\mathrm{MLCK}^{\mathrm{OKO}}$ ) mice, staining with phalloidin revealed decreased expression of the actin cytoskeleton in the cytoplasm and cell membrane of OHCs, whereas its expression remained strong in comparison with that of control (CTR) mice. Nuclei were stained with DAPI (blue). Scale bars, $50 \mu \mathrm{m}$. (B) In MLCK ${ }^{\mathrm{OKO}}$ cochleae, many OHCs showed obvious but weak staining of phosphorylated myosin regulatory light chain (RLC) in contrast to CTR cochleae. Scale bars, $50 \mu \mathrm{m}$.

RLC phosphorylation enhances the formation of polymerized F-actin (27). Thus, we measured RLC phosphorylation in OHCs by staining the phosphorylated RLCs with a specific antibody. In the MLCK ${ }^{\text {OKO }}$ cochleae, many OHCs showed obvious weak staining of the phosphorylated RLCs in contrast to the cochleae of the CTRs (Fig. 4B).

Diameter of MLCK-deficient OHCs is increased. Changes in the volume of hair cells are important for hearing sensitivity, and cell volume is primarily regulated by membrane tethering and cytoskeleton organization $(28,29)$. A comparison of the $\mathrm{OHC}$ diameters between 3-month-old $\mathrm{MLCK}^{\mathrm{OKO}}$ and control mice revealed that the diameters differed (Fig. 5). Compared with the CTR mice, the OHCs of the MLCK ${ }^{\mathrm{OKO}}$ mice were longer and narrower $(7.48 \pm 1.29 \mu \mathrm{m}$ vs. $6.12 \pm 0.88 \mu \mathrm{m}$ in diameter of CTR, $\mathrm{P}<0.01)$.

\section{Discussion}

Genetic and environmental factors are the two main causes of hearing loss. Genetic factors constitute $60 \%$ or more of the main reason of hearing loss (30). Clearly identifying causative genes is the key to the study of hereditary hearing loss. The completion of the Human Genome Project has provided us with an important platform for hereditary hearing loss research. Notably, mice provide a good model system for studying human hearing loss due to the anatomical, functional, physiological and pathological similarities between 
$\mathbf{A}$

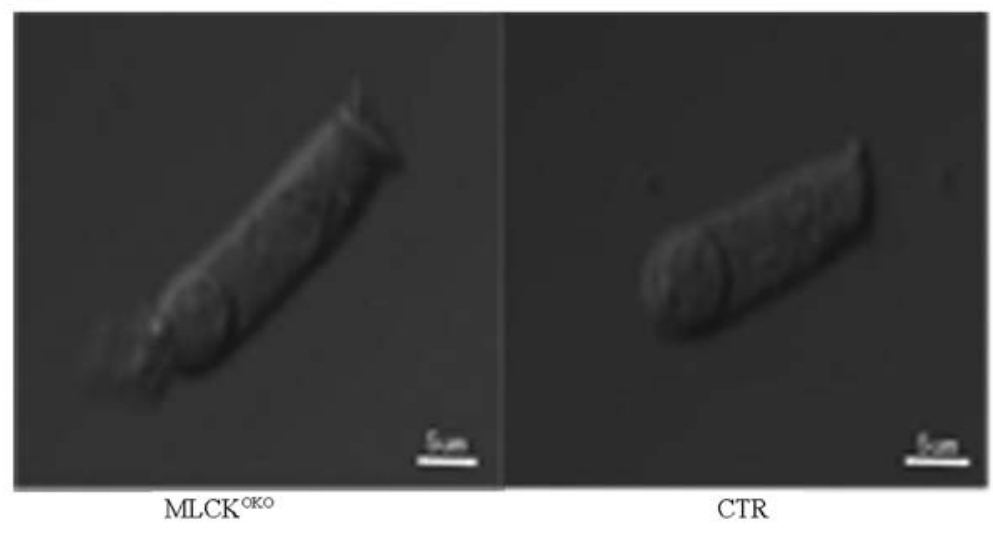

B

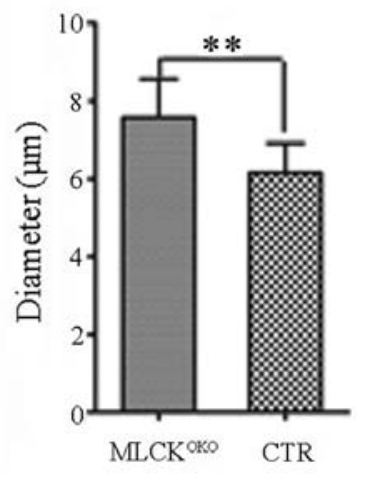

Figure 5. Measuring of the diameter of MLCK-deficient outer hair cells (OHCs). (A) Isolated OHCs were transferred to a chamber filled with D-Hank's solution. Scale bar, $5 \mu \mathrm{m}$. (B) OHCs of MLCK OHC-specific knockout (MLCK $\left.{ }^{\mathrm{OKO}}\right)$ mice $(\mathrm{n}=5)$ had significantly increased diameters compared to the OHCs of control (CTR) mice $(\mathrm{n}=5)$ at the age of 3 months. ${ }^{* *} \mathrm{P}<0.01$, significant difference.

humans and mice. When a candidate gene related to hearing loss in humans is proposed, we can verify the hypothesis by engineering similar mutations in mice.

It has been documented that there are hereditary deafnessrelated genes, including cytoskeletal proteins, extracellular matrix proteins, channel and gap junction proteins, transcription factors, mitochondrial genes and numerous other structures and signaling molecules. However, the mechanisms of action of these genes and their role in hearing remains unclear.

The cytoskeleton is a fibrous protein filament that maintains cell shape, cell movement, information transmission, energy conversion and other functions. The auditory system is complex, and the hair cells in the inner ear play a significant role in hearing. The protein components of the cytoskeleton of hair cells, such as actin, actin-binding protein, myosin, cadherin and Rho GTPases, are closely related to the mechanochemical and -electrical transduction processes in hearing. Mutations of these proteins may lead to abnormalities in the structure and function of the hair cell bodies and stereocilia. Actin and myosin are the basic components of the hair cell structure (31-35). There are a variety of regulatory pathways involved in the interaction of actin and myosin in the smooth muscle. The phosphorylation of the $\mathrm{Ca}^{2+}$-dependent RLC is important in regulating MLCK enzyme activity (36-38). MLCK may play an important role in active $\mathrm{OHC}$ regulation, as the cell body and stereocilia of the OHCs have a large amount of actin and myosin. We specifically deleted the Mylk gene in OHCs by crossing floxed Mylk mice with transgenic mice that expressed Cre in their OHCs. This type of mouse model is useful for clarifying the function of MLCK in OHCs.

$\mathrm{OHCs}$ can regulate cochlear sensitivity to sound stimulation and adjust the gain of the cochlear amplifier to moderate sound intensities. This process involves the stereociliary and somatic motility of OHCs. Thus, we specifically knocked out the Mylk gene in OHCs to elucidate its role in the hearing process.

We evaluated hearing impairment by testing ABRs and DPOAEs in mice. Compared with the controls, 6- to 7-monthold MLCK-deficient mice showed impaired hearing with a
5- to 10-dB SPL increase in ABR thresholds in response to clicks and tones, and 3-month-old MLCK-deficient mice had significantly reduced DPOAE amplitudes at low frequencies. The SEM results revealed that the stereocilia of the OHCs were missing, and stereocilia bundles were scattered on the apex turn. It has been documented that low-frequency hearing corresponds to OHCs in the apex turn. These results demonstrate that the deletion of MLCK has some influence on the active regulation of $\mathrm{OHCs}$.

Our results aslo demonstrated that F-actin and RLC phosphorylation staining in MLCK-deficient OHCs was weak, and that their diameter was increased. MLCK may strengthen the cell membrane through non-kinase activity. MLCK can bundle F-actin and other motor proteins through the non-catalytic $\mathrm{N}$-terminal extension to enhance the cytoskeletal structure and cell membrane. However, there was no significant difference in histology. Perhaps the role of MLCK in the regulation of OHC somatic motility is small, and is more dependent on prestin.

Transducer channels located at the tips of the stereocilia are mechanically gated by mechanoelectrical transduction. The channels open when the cilia are bent toward the tallest one, and close when they bend towards the opposite direction (39). Stereocilia are rich in actin and myosin, and stereociliary motility is associated with $\mathrm{Ca}^{2+}$. The receptor potential of stereocilia is formed by $\mathrm{K}^{+}$influx and cell depolarization. It opens L-type voltage-dependent calcium channels and allows $\mathrm{Ca}^{2+}$ influx, causing a series of reactions (40). This model predicts that MLCK deletion can alter the architecture of the stereocilia and thus affect the transduction channels at the tips of the stereocilia.

\section{Acknowledgements}

We thank Professor Minsheng Zhu, Dr Weiqi He, Dr Yajing Peng, Dr Chen Chen, Dr Chenghai Zhang, Dr Yanning Qiao, Dr Caiping Chen and Dr Tao Tao of the Model Animal Research Center of Nanjing University in China. This study was supported by grants from the National Natural Science Funding of China (nos. 30973302 and 81371090), and the Medical Youth Priming Project of Nanjing (QYK1162). 


\section{References}

1. Thomas PC: Of specialty interest: publications of the National Institute on Deafness and Other Communication Disorders. ORL Head Neck Nurs 20: 26-30, 2002.

2. Battey JF Jr: News from the National Institute on Deafness and Other Communication Disorders. Am J Otol 19: 263-265, 1998.

3. Steel KP and Kros CJ: A genetic approach to understanding auditory function. Nat Genet 27: 143-149, 2001.

4. Arnos KS: The implications of genetic testing for deafness. Ear Hear 24: 324-331, 2003.

5. Krendel M and Mooseker MS: Myosins: tails (and heads) of functional diversity. Physiology 20: 239-251, 2005.

6. Etournay R, Zwaenepoel I, Perfettini I, Legrain P, Petit C and El-Amraoui A: Shroom2, a myosin-VIIa- and actin-binding protein, directly interacts with ZO-1 at tight junctions. J Cell Sci 120: 2838-2850, 2007.

7. Friedman TB, Sellers JR and Avraham KB: Unconventional myosins and the genetics of hearing loss. Am J Med Genet 89 147-157, 1999.

8. Mermall V, Post PL and Mooseker MS: Unconventional myosins in cell movement, membrane traffic, and signal transduction. Science 279: 527-533, 1998.

9. Libby RT and Steel KP: The roles of unconventional myosins in hearing and deafness. Essays Biochem 35: 159-174, 2000.

10. Redowicz MJ: Myosins and deafness. J Muscle Res Cell Motil 20 : 241-248, 1999.

11. Ashmore JF: A fast motile response in guinea-pig outer hair cells: the cellular basis of the cochlear amplifier. J Physiol 388 323-347, 1987.

12. Dallos $\mathrm{P}$ and Fakler B: Prestin, a new type of motor protein. Nat Rev Mol Cell Biol 3: 104-111, 2002.

13. Dulon D and Schacht J: Motility of cochlear outer hair cells. Am J Otol 13: 108-112, 1992

14. Santos-Sacchi J: New tunes from Corti's organ: the outer hair cell boogie rules. Curr Opin Neurobiol 13: 459-468, 2003.

15. Knipper M, Zimmermann U, Köpschall I, Rohbock K, Jüngling S and Zenner HP: Immunological identification of candidate proteins involved in regulating active shape changes of outer hair cells. Hear Res 86: 100-110, 1995.

16. Yamamoto N, Okano T, Ma XF, Adelstein RS and Kelley MW Myosin II regulates extension, growth and patterning in the mammalian cochlear duct. Development 136: 1977-1986, 2009.

17. Schoenwaelder SM and Burridge $\mathrm{K}$ : Bidirectional signaling between the cytoskeleton and integrins. Curr Opin Cell Biol 11: 274-286, 1999.

18. Bresnick AR: Molecular mechanisms of nonmuscle myosin-II regulation. Curr Opin Cell Biol 11: 26-33, 1999.

19. Szaszi K, Kurashima K, Kapus A, Paulsen A, Kaibuchi K, Grinstein $\mathrm{S}$ and Orlowski J: RhoA and rho kinase regulate the epithelial $\mathrm{Na}^{+} / \mathrm{H}^{+}$exchanger NHE3. Role of myosin light chain phosphorylation. J Biol Chem 275: 28599-28606, 2000.

20. Aromolaran AS, Albert AP and Large WA: Evidence for myosin light chain kinase mediating noradrenaline-evoked cation current in rabbit portal vein myocytes. J Physiol 524: 853-863, 2000.

21. Zhu GJ, Wang F, Chen C, Xu L, Zhang WC, Fan C, Peng YJ, Chen J, He WQ, Guo SY, Zuo J, Gao X and Zhu MS: Myosin light-chain kinase is necessary for membrane homeostasis in cochlear inner hair cells. Plos One 7: e34894, 2012.

22. Birukov KG, Schavocky JP, Shirinsky VP, Chibalina MV, Van Eldik LJ and Watterson DM: Organization of the genetic locus for chicken myosin light chain kinase is complex: multiple proteins are encoded and exhibit differential expression and localization. J Cell Biochem 70: 402-413, 1998.
23. Smith AF, Bigsby RM, Word RA and Herring BP: A 310-bp minimal promoter mediates smooth muscle cell-specific expression of telokin. Am J Physiol 274: C1187-C1195, 1998.

24. Watterson DM, Schavocky JP, Guo L, Weiss C, Chlenski A, Shirinsky VP, Van Eldik LJ and Haiech J: Analysis of the kinaserelated protein gene found at human chromosome $3 \mathrm{q} 21$ in a multi-gene cluster: organization, expression, alternative splicing, and polymorphic marker. J Cell Biochem 75: 481-491, 1999.

25. Li MY, Tian Y, Fritzsch B, Gao JG, Wu XD and Zuo J: Inner hair cell Cre-expressing transgenic mouse. Genesis 39: 173-177, 2004

26. Song L, McGee JA and Walsh EJ: Consequences of combined maternal, fetal and persistent postnatal hypothyroidism on the development of auditory function in Tshrhyt mutant mice. Brain Res 1101: 59-72, 2006

27. Goeckeler ZM: Myosin light chain kinase-regulated endothelial cell contraction: the relationship between isometric tension, actin polymerization, and myosin phosphorylation. J Cell Biol 130: 613-627, 1995.

28. Li J and Verkman AS: Impaired hearing in mice lacking aquaporin-4 water channels. J Biol Chem 276: 31233-31237, 2001.

29. Frolenkov GI, Belyantseva IA, Friedman TB and Griffith AJ: Genetic insights into the morphogenesis of inner ear hair cells. Nat Rev Genet 5: 489-498, 2004.

30. Marazita ML, Ploughman LM, Rawlings B, Remington E, Arnos KS and Nance WE: Genetic epidemiological studies of early-onset deafness in the U.S. school-age population. Am J Med Genet 46: 486-491, 1993.

31. Lynch ED, Lee MK, Morrow JE, Welcsh PL, Leon PE and King MC: Nonsyndromic deafness DFNA1 associated with mutation of a human homolog of the Drosophila gene diaphanous . Science 278: 1315-1318, 1997.

32. Liu XZ, Walsh J, Mburu P, Kendrick-Jones J, Cope MJ, Steel KP and Brown SD: Mutations in the myosin VIIA gene cause nonsyndromic recessive deafness. Nat Genet 16: 188-190, 1997.

33. Wilson SM, Householder DB, Coppola V, Tessarollo L, Fritzsch B, Lee EC, Goss D, Carlson GA, Copeland NG and Jenkins NA: Mutations in Cdh23 cause nonsyndromic hearing loss in waltzer mice. Genomics 74: 228-233, 2001.

34. Lalwani AK, Goldstein JA, Kelley MJ, Luxford W, Castelein CM and Mhatre AN: Human nonsyndromic hereditary deafness DFNA17 is due to a mutation in nonmuscle myosin MYH9. Am J Hum Genet 67: 1121-1128, 2000.

35. Grimsley-Myers CM, Sipe CW, Geleoc GS and Lu X: The small GTPase Rac1 regulates auditory hair cell morphogenesis. J Neurosci 29: 15859-15869, 2009.

36. Walker JW, Gilbert SH, Drummond RM, Yamada M, Sreekumar R, Carraway RE, Ikebe M and Fay FS: Signaling pathways underlying eosinophil cell motility revealed by using caged peptides. Proc Natl Acad Sci USA 95: 1568-1573, 1998.

37. Ding HL, Ryder JW, Stull JT and Kamm KE: Signaling processes for initiating smooth muscle contraction upon neural stimulation. J Biol Chem 284: 15541-15548, 2009.

38. Breckenridge MT, Dulyaninova NG and Egelhoff TT: Multiple regulatory steps control mammalian nonmuscle myosin II assembly in live cells. Mol Biol Cell 20: 338-347, 2009.

39. Cheatham MA, Huynh KH, Gao J, Zuo J and Dallos P: Cochlear function in Prestin knockout mice. J Physiol 560: 821-830, 2004.

40. Mills DM and Schmiedt RA: Metabolic presbycusis: differential changes in auditory brainstem and otoacoustic emission responses with chronic furosemide application in the gerbil. J Assoc Res Otolaryngol 5: 1-10, 2004. 